\title{
As redes de suporte social informal como fontes de provisão social em Portugal: o caso da população idosa
}

Sónia Guadalupe \& Júlia Cardoso*

Resumo: Os indicadores de envelhecimento na população portuguesa colocam Portugal como um dos países mais envelhecidos do mundo, sendo os idosos um grupo populacional socialmente vulnerável. A vulnerabilidade, resultante de trajetórias ao longo da vida com acúmulo progressivo de desvantagens, tem como determinantes os fortes níveis de perda de autonomia com o avançar da idade, o risco de isolamento social, o elevado risco de exclusão e de pobreza, colmatado pelo forte impacte das transferências sociais no rendimento, a par das transformações na sociedade portuguesa, particularmente na morfologia das famílias e na relação com o trabalho. Este quadro de vulnerabilidade tem encontrado resposta na expansão de políticas de bem-estar no contexto do desenvolvimento do Estado-providência, mas também na provisão informal, sobretudo das famílias. Em tempos recentes, assistimos a uma inversão na trajetória providencial por parte do Estado português, cada vez mais recuado, agudizando-se a responsabilidade familiar.

O artigo apresenta uma reflexão sobre a relevância do suporte social informal na proteção social em Portugal no que concerne à população idosa, problematizando particularmente o papel providencial das famílias num contexto de austeridade, a partir de documentação e literatura produzida no e sobre o contexto social português.

Palavras-chave: provisão social informal; Estado-providência, família, idosos, envelhecimento.

\section{A relevância das redes de suporte social informal na provisão social em Portugal}

omo fontes de recursos e de suporte social (quer material, instrumental, informativo ou emocional), as redes sociais pessoais, eminentemente familiares, têm sido um dos pilares da provisão social informal, assumindo centralidade nos processos de intervenção social.

Apesar de o Estado se ter assumido como um produtor central da providência societal nas sociedades europeias do pós-guerra, nas "sociedades seguradoras" como Ihes chamou Robert Castel (2003), este constitui um dos eixos da "matriz tripolar da regulação social" (Santos, 1995) constituída por três formas de providência: a

\footnotetext{
* Sónia Guadalupe é doutora em serviço social pelo Instituto Universitário de Lisboa (ISCTE), doutora em saúde mental pela Universidade do Porto, professora no Instituto Superior Miguel Torga, Coimbra, Coimbra Portugal. <soniaguadalupe@ gmail.com>.

Júlia Cardoso é doutora em serviço social pelo Instituto Universitário de Lisboa (ISCTE), Lisboa (PO), professora no ISCTE-IUL e no Instituto Superior de Serviço Social de Lisboa da Universidade Lusíada (Portugal), Lisboa, Portugal. $<j u l i a c a r d o s o @ s a p o$. pt>.
} 
estatal, a mercantil e a comunitária. A triangulação resulta em diferentes formas de organização coletiva a que convencionámos a designação de Estado providência (adotando a designação francófona, ou Estado de bem-estar, na versão anglófona, ou Estado na conceção germânica). A tríade de modelos de bem-estar caracterizada por Esping-Andersen (1990), baseada na ideia de "desmercadorização", reportando-se ao grau de manutenção de um nível de vida socialmente aceitável independentemente da participação no mercado, veio posteriormente a integrar a ideia de "desfamiliarização" (Esping-Andersen, 1999), remetendo para o nível de esforço de bem-estar que fica dependente da ação familiar ou para o grau de abrandamento da responsabilidade familiar na provisão social face às políticas sociais. A ideia de "desfamiliarização" surge na sequência de críticas à tipologia proposta por Esping-Andersen por esta não integrar o papel da mulher ou da economia informal (Andrade, 2009). Explicita Esping-Andersen (1999) que a categoria não se opõe à família, querendo antes sublinhar a redução de suas responsabilidades na proteção, constituindo-se como condição para a mulher se mercadorizar, dimensões relevantes na configuração do bem-estar. Nesta conceção, em sentido oposto, os modelos familistas ou familiaristas de welfare exigem uma maior participação das famílias nessa provisão e um menor investimento estatal nas políticas públicas (Saraceno, 2010; Silva, 2002; Mioto, 2008).

Apesar da resistência ao desmantelamento ameaçador do quase-Estado-providência português (Santos, 1993; Santos e Ferreira, 2002) e das reconfigurações a que temos assistido nas últimas duas décadas- sobretudo por via da implementação de um projeto neoliberal que tem modificado radicalmente as relações de trabalho - de mercado e de proteção social, este tem persistido, ainda que com um nível cada vez mais baixo de despesa social, de redistribuição e de eficácia das políticas sociais, o que deixa um lastro de desproteção perante várias eventualidades da vida dos cidadãos ou, pelo menos, uma enorme incompletude na sua proteção e bem-estar social.

Este desprovimento estatal, que em maior ou menor grau marca o sistema público português de proteção social, tem sido contrabalançado pela existência proeminente do que conceptualizou como sociedade providência, baseada nas relações interpessoais e de entreajuda, sustentadas na reciprocidade de um circuito afetivo (Portugal, 2000; 2011; 2014; Santos, 1993; 1994; 1995; Serapioni, 2005; Wall, Aboim, Cunha \& Vasconcelos, 2001), constituindo-se como mecanismo compensatório face à insuficiência estatal (Carvalho \& Almeida, 2003; Sposati \& Rodrigues, 1995). As redes sociais pessoais são a malha que tece a sociedade providencial. As famílias destacam-se como componentes centrais destas redes no apoio social que assumem informalmente plano da proteção pessoal e familiar, pelo que tem sido evidenciado o forte familismo das redes sociais em Portugal, traço caracterizado por uma forte 
entreajuda sobretudo baseada no parentesco (Aboim, Vasconcelos \& Wall, 2013; Fernandes, 2001; Portugal, 2011; 2014; Wall, Aboim, Cunha \& Vasconcelos, 2001). Aliás, Robert Castel (2003: 51) fala na ideia de "família-providência" como metáfora para a ação de regulação coletiva que a família (alargada à comunidade de proximidade) foi capaz de assegurar ao longo da história, mobilizando solidariedades "naturais", na ausência de instituições especializadas, em sociedades sem um domínio "social" organizado. Carvalho (2010: 268) afirma mesmo que o exercício vital das famílias se assemelha às funções das políticas sociais porque ambas pretendem dar conta da reprodução e da proteção dos que se encontram sob sua tutela, assumindo "funções correlatas e imprescindíveis ao desenvolvimento e à proteção social dos indivíduos".

Boaventura Sousa Santos (1994: 64) entende que a sociedade providência é organizada informalmente segundo modelos tradicionais de solidariedade constituídos por "redes de relações de interconhecimento, de inter-reconhecimento e de ajuda mútua baseadas em laços de parentesco, de vizinhança e comunitários", que representam microssistemas de apoio onde se estabelecem trocas não mercantis de bens e de serviços (Hespanha, 1993). Tais nichos relacionais são eminentemente compostos por laços de natureza primária ou de solidariedade mecânica, na conceção de Émile Durkheim (apud Paugam, 2009).

Estas e outras características são atribuídas às formas de organização do bem-estar nos países da Europa do Sul (Ferrera, 2000; Silva, 2002), propondo Pedro Adão e Silva (2002) a possibilidade de autonomização da sociedade providência como dimensão variante das solidariedades primárias familiares na análise das dinâmicas de produção do bem-estar tradicionalmente centradas na proteção social, no mercado de trabalho e na família, para compreender as suas especificidades. Tais idiossincrasias resultam em grande medida das características que encontramos nas famílias desta região da Europa em certos períodos sócio-históricos, determinados por regimes dominantes de produção e de industrialização, pelas relações com a Igreja e pelos processos de modernização social e de democratização (Guerrero \& Naldini, 2007). Ainda que nas décadas mais recentes se tenham verificado marcantes mudanças demográficas, Guerrero e Naldini (2007) abordam o chamado modelo familiar do sul da Europa do final do século XX como um tipo ideal sustentado em cinco marcadores da relação entre a família e o Estado:

i. a alta solidariedade social existente a par da solidariedade que a legislação supõe;

ii. a fraca pluralização nas famílias ditas clássicas a par do subdesenvolvimento nas políticas de família e de habitação; 
iii. a baixa taxa de fecundidade e a tendência para a redução no número de filhos a par do baixo investimento em serviços públicos de cuidados a dependentes;

iv. a baixa participação dos homens em trabalho não remunerado a par das políticas não promotoras de igualdade de género;

v. o baixo nível de emprego a tempo parcial e longas jornadas de trabalho, a par da falta de políticas que favoreçam a conciliação da vida familiar com o trabalho.

Vários autores chamam a atenção para a necessidade de desconstruir a ideia de que a família extensa ou o parentesco alargado caracterizam estritamente a Europa pré-moderna (Aboim, Vasconcelos \& Wall, 2013; Fernandes, 2001; Vasconcelos, 2002), enfatizada pelas conceções durkheimianas e parsonianas de contração e isolamento familiar, pela separação progressiva entre núcleo e parentela, pois tal é contrariado pela evidência demográfica e sociológica produzida a partir do final dos anos 1950, apontando para uma morfologia familiar diversa, ainda que dominantemente nuclear, mas na qual não se desvaloriza a vitalidade das relações de parentesco extenso.

Numa sociedade marcada pela semiperiferia em que o nosso "Estado providência nunca atingiu o seu pleno desenvolvimento" (Santos, 1995: ii) e apresenta uma crise instalada, a sociedade providência assume

um conjunto de mecanismos e práticas de base social que, de facto (e não de direito), constrói garantias de enfrentamento das adversidades e reduz a precariedade das condições de viver (Sposati \& Rodrigues, 1995: 94).

Esta assegura, assim, algum do bem-estar e da proteção social (Santos, 1995) baseada em "ajudas que não chegam a constituir obrigatoriedades, mas disponibilidades", substituindo disposições gerais por regulações ad hoc (Sposati \& Rodrigues, 1995: 102). Neste sentido, diz-nos Nunes (1995) que nunca a poderemos considerar como a forma de providência social principal ou exclusiva, pois há descoincidência entre o tipo de bens e de serviços passíveis de serem fornecidos face aos que o Estado pode proporcionar, e encerra evidentes limitações, atendendo a que o reconhecimento de pertença se baseia no que o autor apelida de ancoragem e de recrutamento (através do nascimento, casamento/cooptação ou afinidade), numa lógica particularista e seletiva, não se constituindo como garante de proteção continuada nem de direitos gerais e idênticos ou homogeneizantes para todos, não correspondendo ao modelo de 
sociedade moderna e democrática (Hespanha, 1993), apesar da ideia de recriação do laço social. Nunes (1995) assinala ainda que o modelo de cidadania baseado na sociedade providência promove a reprodução das desigualdades sociais, sendo a família perspetivada como o sistema primordial de reprodução social (Bourdieu, 1993; Leandro, 2011; Shultheis, 1997; Vasconcelos, 2002; 2011; Wall, Aboim, Cunha \& Vasconcelos, 2001). Vasconcelos (2002) sublinha que as redes de entreajuda não existem no vazio social, sendo morfologicamente estruturadas e caracterizadas por seu posicionamento no tecido social com os seus processos de diferenciação e de perpetuação nas categorias sociais, entendendo as práticas de entreajuda e de solidariedade nas famílias como estratégias ativamente subsidiárias da reprodução social.

A família pode, assim, ser enquadrada na modalidade de proteção social de âmbito privado não mercantil, a par de outras instituições tradicionais filantrópicas e religiosas, contrapondo esta modalidade à de âmbito público assumida pelo Estado (Di Giovanni, 1998 apud Mioto, 2008). Por seu lado, Sposati e Rodrigues (1995) distinguem um circuito íntimo e outro exterior na sociedade providência, ambos com manifestações individuais e coletivas. No primeiro a solidariedade constrói-se com base na identidade da carência e da partilha do risco social, sobretudo num modo de mutualidade informal e recíproca; no segundo esta decorre da ideia do dever ético e moral para com o outro, associando-se ao que as autoras designam por solidariedade de partilha e de concessão, fundadas, respetivamente, na igualdade social e no princípio de subsidiariedade. Na relação com a esfera pública, a família é considerada como a expressão máxima da vida privada e lugar de intimidade, enquanto nicho afetivo de relações promotoras de socialização e de vínculos de inclusão social, constituindo-se como condição objetiva e subjetiva de pertença (Carvalho, 2010) e de filiação (Castel, 2003).

Na discussão sobre a relação entre estas formas de provisão social, surgiu a ideia do pluralismo no bem-estar a partir dos anos 1980. Martin (1995) refere-se ao "welfare-mix" que preconiza

uma combinação dos recursos e meios mobilizáveis junto do Estado, dos parentes, mas também junto do mercado ou ainda das iniciativas privadas, associativas, beneficentes e não lucrativas (Martin, 1995: 55).

Encontram-se diversas propostas de modelos mistos de proteção social, com maior ou menor retração do papel do Estado ou com a sua reconfiguração, fomentando a sua função financiadora e reguladora (Marques, 2008), mas, definitivamente, as fronteiras entre a responsabilidade pública e privada têm sido redesenhadas (Daatland \& Lowenstein, 2005). Martin (1995) afirma mesmo que 
a sociabilidade, a entreajuda, o apoio dos conhecidos ou as amizades dos parentes transformaram-se, assim, em novas perspectivas para as políticas sociais Martin (1995: 62),

ideia sublinhada por Hespanha (1993) quando defende que

\begin{abstract}
a presença de sistemas informais de suporte no seio dos grupos primários e das comunidades constituem uma forte tentação para o Estado, pressionado por dificuldades financeiras, em recuar nas suas políticas sociais, abandonando algumas de entre elas, mais custosas, ou em reduzir os direitos sociais sem uma real contrapartida (Hespanha, 1993: 18),
\end{abstract}

sendo analisado no ponto seguinte o destacado papel providencial que a família tem assumido socialmente.

\title{
As famílias como sustentáculo das redes de suporte social informal
}

O apelo encantatório das solidariedades primárias e da família tem subsistido, apesar das ideias que reclamam a dissolução e a extinção da família (Sawaia, 2010; Volpi, 2007). A amplificação da diversidade de configurações e pluralização de estruturas e de modelos familiares das sociedades hodiernas (Erera, 2002; Flandrin, 1995; Williams, 2010; Zanata, 2008), tem levado a adjetivar a família como incerta (Roussel, 1989 apud Esteves, 1991) ou como "líquida", adotando a terminologia de Zygmunt Bauman, sublinhando a sua mutabilidade, mas não necessariamente o seu fim.

Ganham relevo novas formas de organização e de relação com o processo de democratização familiar (Williams, 2010) e com o impacte de mudanças vincadas face ao passado demográfico (Rosa, 2015), mudanças estas marcadas pela "dessacralização do casamento, pela desinstitucionalização das relações dos casais e pela desmatrimonialização dos nascimentos" (Rosa, 2015: 36; Rosa \& Chitas, 2013). Este panorama ampara conceções que espelham a ideia da existência de uma "crise de valores" na família evocada frequentemente pelas chamadas teses pessimistas da imoralização (Williams, 2010) que perspetivam as mudanças demográficas a que assistimos nas últimas três décadas na Europa ocidental como sintoma do declínio moral, da falta de solidariedade, da falta de estabilidade social, do domínio de um individualismo egoísta (Williams, 2010), assim como da valorização do privado e da subjetividade (Sawaia, 2010). 
Ao assumir uma entidade proteiforme, as mudanças nos modelos familiares interagem com outras mudanças que têm neles impactes diversos, quer sejam mudanças demográficas, culturais, económicas ou políticas, sendo necessário investir na compreensão de aspetos que não emergem da análise das estatísticas per si, tais como da variabilidade, das singularidades, dos processos, do significado das respostas à mudança, ou da representação da instabilidade, das inconsistências e contradições.

As transmutações têm sido sucessivas, mas apesar destas, Balandier (1986) sublinha a ancestralidade e universalidade da família, evidenciada a sua enorme capacidade de resistência, adaptação e dinâmica. Sendo, por isso, considerada por Bourdieu (1993) uma categoria realizada em permanente e contínua transformação. Diacronicamente,

\footnotetext{
a família não é apenas o que resiste ao tempo, mas [...] o que se constrói no tempo, relativamente ao passado, ao presente e ao devir do futuro (Leandro, 2011: 105).
}

Não admira pois, que [...] a família continue a funcionar como um refúgio onde se espera encontrar protecção e apoio para colmatar as falhas que possam existir a nível de outras formas de laços sociais (Leandro e Ferreira, 2011: 48),

num movimento de desinstitucionalização e de desvinculação da proteção social estatal, com o avanço do neoliberalismo e a chamada crise do Estado providência, com forte retração e diminuição de sua ação na segurança e na garantia de direitos.

A fulcralidade da família como fonte de suporte informal parece ser incontornável no contexto sociocultural português (Portugal, 2011; 2014), constituindo "o núcleo central da sociedade e o primeiro responsável pela proteção dos seus membros", de acordo com a asserção defendida por Nunes (2015: 47), numa reflexão sobre ética e família. O código civil português atualmente em vigor reflete em grande medida esta premissa axiológica, ainda que não hierarquizada, associando à vinculação da parentalidade os deveres de respeito, auxílio e assistência, e à vinculação da conjugalidade os deveres de respeito, fidelidade, coabitação, cooperação (socorro e auxílio mútuo) e assistência (prestação de alimentos e contributo para encargos da vida familiar), direito este fundado na reciprocidade entre ascendentes e descendentes. Define-se, assim, num eixo moral fundamentado na obrigação recíproca (Sarti, 2010).

Porém, emergem tendências de perda dessa centralidade ocupada pelo sistema familiar, nomeadamente na provisão social informal e no cuidar, sugerindo Fiona 
Williams (2010), a partir das conclusões dos seus estudos, a existência de diferenças face ao passado no que concerne ao tipo de compromisso assumido entre as pessoas, agora menos dependentes dos laços de sangue e de casamento. Contudo, a autora adverte que a mudança da natureza do compromisso não traduz o seu enfraquecimento. Este argumento contraria as teses pessimistas, da imoralização, que têm como opositoras as teses otimistas, da democratização, nos debates sobre os papéis, as prioridades familiares e o lugar do cuidar nas relações. As primeiras perspetivam as mudanças nas famílias associando-Ihe declínio moral, individualismo, instabilidade e falta de solidariedade social, num "declínio dos valores de dedicação", como refere De Singly (apud Lesemann \& Martin, 1995); já as segundas evidenciam uma quebra com convenções e constrangimentos (Williams, 2010). A ideia de família ora é enaltecida, ora é demonizada no seio das teorias sociais e humanas (Sawaia, 2010), mas raramente tem sido ignorada.

Pedroso e Branco (2008) sublinham a flexibilidade e fluidez dos novos cenários familiares, sugerindo que não possamos falar de crise da família mas da crise de um certo modelo, que os autores descrevem como

estável e harmoniosa, afectiva e fecunda, governada por regras rígidas de divisão do trabalho e assente numa hierarquia entre homem e mulher, pais e filhos (Pedroso \& Branco, 2008: 55).

É de se considerar, todavia, que os autores se reportam à crise de um mito: o modelo unívoco de família, dito tradicional e normativo. Contrariamente aos argumentos pessimistas que defendem que as mudanças na vida familiar conduziriam a uma perda no compromisso e a um aumento do individualismo egoísta, as pessoas procuram sustentar as relações que valorizam (Williams, 2010). Fiona Williams (2010) sublinha que as conclusões dos estudos sobre mudanças nas teias relacionais não indicam a sua fragilização, mas sim uma nova padronização nos compromissos relativos à intimidade, às relações próximas e ao cuidado, extravasando fronteiras de sangue, casamento ou cultura. "O laço familiar persiste apesar das inúmeras mutações e figurinos da família”, como atesta Maria Engrácia Leandro (2011: 105), reafirmando os postulados de Balandier (1986) e de Bourdieu (1993).

A elasticidade e a plasticidade são reveladas ao longo da história, evidenciando-se que, "mesmo com este turbilhão de mudanças, a família continua a usufruir de muita pujança e a ser extremamente valorizada" (Leandro, 2011: 96). Aparentemente,

sob muitos e variados aspectos da vida individual, familiar e social vive-se sob o império do efémero e do inédito, da procura do novo 
pelo novo, da dificuldade em assumir compromissos duradoiros (Leandro, 2011: 103),

o que pode fundamentar juízos de valor depreciativos, mas as famílias contemporâneas têm vindo a libertar-se de constrangimentos tradicionais que pesavam sobre a família, parecendo que hoje podemos ser simultaneamente mais livres e mais expostos aos riscos, mais responsáveis e mais incertos, mais autónomos e mais frágeis, como afirma Castel (1991).

Assim, de entre os fenómenos sociais complexos, a família é aquele que mais tem resistido se tem (re)construído no tempo, podendo afirmar-se a família como uma construção social permanente (Leandro, 2011). Ainda que constitua uma identidade narrativa emergente da interação relacional construída socialmente, a sua corporização é assumida em diversos campos da vida social. Todos falamos da ideia de família assim como de famílias, singularizando a abstração conceptual e pluralizando as famílias concretas na sua diversidade. Na sua singularidade e diversidade, serão também diversas as formas como se evidencia o papel central na provisão social informal que lhe é atribuído.

Na abordagem ao sistema familiar como elemento-chave na provisão social, este surge como fator de justificação do não intervencionismo estatal e de desconstrução, de refilantropização e de uma reprivatização da proteção (Ferreira, Moraes, Badaró \& Franco, 2004; Pereira, 2006; Portugal, 2000; Serapioni, 2005; Yazbeck, 2001), associadas às tendências de ativação, de autonomização, de individualização (Andrade, 2009; Branco \& Amaro, 2011; Duvoux, 2012), de seletividade e de focalização (Andrade, 2009; Pereira, 2006; Rodrigues, 2008) nas políticas de bem-estar social, assim como à restrição no acesso às medidas de política social patente nas opções do plano de austeridade que tem vigorado em Portugal recentemente $^{1}$, orientado por opções político-ideológicas marcadamente neoliberais (Capucha, 2014; Hespanha, Ferreira \& Pacheco, 2013). Concomitantemente, engrossa também o terceiro sector ou sector solidário, no quadro da retração das políticas progressistas de bem-estar (Joaquim, 2015; Santos, 1999), ainda que esta relação remeta para um aprofundamento do qual não nos ocuparemos no presente texto. Neste sentido, assiste-se a uma regressão por metamorfose dos direitos sociais em deveres morais (Yazbek, 2001), essencialmente a assumir pelos cidadãos e pelas famílias, mostrando-se a relação entre solidariedades familiares e públicas "simultaneamente interdependentes e irredutíveis umas às outras" (Lesemann \& Martin, 1995: 124). Paradoxalmente, a par, as condições para que as famílias assumam o seu papel providencial, quer pelas transformações que têm vindo a viver os sistemas familiares, quer pelas exigências impostas aos membros das famílias em idade

1. Referimonos ao plano de austeridade decidido pelo XII Governo Constitucional da República Portuguesa, com base no memorando da Troika constituída pela Comissão Europeia, pelo Banco Central Europeu e pelo Funco Monetário Internacional. 
ativa pelo sistema económico-financeiro e as limitações no direito ao e no trabalho, vêm limitar, fragmentar, atomizar ou mesmo anular a sua potencial centralidade na proteção social.

Ao retomar as ideias contrárias de "desfamilização" e de "familização", a partir do preconizado por Esping-Andersen (1999), pode-se afirmar que a última tendência tem dominado os sistemas de proteção social de recorte neoliberal, sendo tal processo apelidado de "neoliberalismo familiarista" por De Martino (2001 apud Mioto, 2008). O retrocesso nas políticas de garantia de direitos tem estado diretamente associado à redescoberta da autonomia familiar, à supervalorização, ao "recrudescimento da ideia de família como ator fundamental na provisão de bem-estar" (Mioto, 2008: 137), ou, por outras palavras à sua "redescoberta enquanto fonte privada de bem-estar" (Andrade, 2009: 58). Andrade (2009) sugere que o

retorno contemporâneo da família, enquanto centro privilegiado da proteção social, não só pode ser considerado uma nostalgia, mas um enfoque conservador da política social (Andrade, 2009: 66),

sendo fulcral a clarificação da matricialidade sociofamiliar das políticas. Correndo o risco de descontextualizar e desfocalizar as propostas dos autores, podemos enquadrar esta análise, em certa medida, numa tendência de privatização da cidadania, como Ihe chama Dupas (2005: 177 apud Silveira, 2013) ou num processo de descidadanização (Boron, 2001 apud Silveira, 2013).

Embora estas tendências assumam uma expressão vincada nos países do sul da Europa, desde as últimas décadas do século XX verificam-se as mesmas orientações de governação neoliberal na generalidade dos países capitalistas, nomeadamente nalguns países da América Latina, onde o familismo assume um papel central nas políticas sociais (Andrade, 2009; Campos \& Mioto, 2003; Castilho \& Carloto, 2010; Franzoni, 2007; Jesus, Azevêdo \& Silva, 2011; Mioto, 2008; Pereira, 2006; Sunkel, 2006). Verifica-se, de facto, que a família tem sido chamada a aprofundar as suas responsabilidades na proteção dos seus membros mas, simultaneamente, tem visto acrescidas as dificuldades de ação num contexto adverso e dinâmico, pontuado por condições de vida objetivas agravadas (Jesus, Azevêdo \& Silva, 2011; Mioto, 2008), pelos riscos e pelas incertezas. Note-se que esta transferência de responsabilidades das políticas públicas para o espaço privado, representado pelas famílias, não é isenta de contrariedades, nomeadamente atendendo à operacionalização cada vez mais incerta do conceito de família no desenho das políticas sociais, pela diversidade de modelos de bem-estar, mas, sobretudo, pela pluralidade de formas de família, designando-a Potyara Pereira (2006: 41) como "fenómeno plural". O papel subsidiário, 
complementar ou central da família varia consoante a configuração do modelo de proteção social (Lesemann \& Martin, 1995), numa interação complexa entre costumes e tradições culturais, expectativas sociais e ideologia política, definidora das variantes nas fronteiras entre esfera pública e familiar, que diferem necessariamente de sociedade para sociedade (Bazo, 2008).

Campos e Mioto (2003) identificam três modelos analíticos relativos à família no âmbito dos diferentes sistemas de provisão social:

i. o da família do provedor masculino;

ii. o do familismo; e

iii. o da família nos sistemas de proteção social de orientação social-democrática.

O primeiro evoca um modelo dito tradicional e baseia-se na existência de uma solidariedade familiar que implica trocas intergeracionais e de género, assimétricas, com um "chefe de família" redistribuidor, onde persiste uma "naturalização" das obrigações familiares; o segundo encara a família como principal sistema responsável pelo bem-estar social, com transferências diretas às famílias, tendencialmente com base na universalidade; o terceiro tende a socializar antecipadamente os custos enfrentados pela família, sem esperar que a sua capacidade se esgote, com transferências aos indivíduos e não às famílias, com oferta de serviços sociais de apoio aos encargos familiares, tendencialmente com cobertura universal da população (Campos \& Mioto, 2003). Na europeu, Mioto (2008) faz notar que o terceiro modelo corresponderá aos sistemas de proteção social dos países escandinavos, e o segundo aos países do sul. Um estudo europeu sobre a relação entre a provisão formal e informal, que adota o conceito de capital social - baseado na análise dos dados do Eurobarómetro sobre 27 países - identifica diferentes regimes: os países escandinavos e a Holanda apresentam os maiores níveis de todas as formas de capital social; na Europa do Sul e do Leste aparece como mais relevante o capital social informal, no sul principalmente sob a forma de apoio familiar, verificando-se no Leste também o papel importante do apoio informal fora da família (Pichler \& Wallace, 2007).

Ferreira e Monteiro (2015) fazem notar que a dita crise financeira vivida em Portugal e na Europa desde 2008 forçou um retrocesso na trajetória nas políticas sociais que se diferenciavam do modelo tradicional de proteção social do sul da Europa. O recuo no bem-estar formal, as políticas de cortes nos salários e rendimentos das famílias e nas transferências sociais teve como consequência um reforço da socie- 
dade providencial informal, isto é, da solidariedade provida pelas redes sociais e pelas famílias (Ferreira \& Monteiro, 2015; Portugal, 2014). O traço de refamilização do bem-estar está bem patente na ação compensatória das famílias diante da desproteção social estatal, constituindo a solidariedade intergeracional nas famílias um forte fator de estabilidade e de coesão social num contexto de agravada incerteza (Ferreira \& Monteiro, 2015; Frade \& Coelho, 2015).

O perfil focalizado, compensatório e residual das políticas sociais, acentua-se e expande-se (Mioto, 2008). Ao mesmo tempo, atribuem-se às famílias acrescidos níveis de responsabilização moral e legal pela provisão social intergeracional, mas são dadas cada vez menos condições concretas para que exerçam efetivamente tais responsabilidades. Capucha (2014: 125) adverte que, no contexto que marca política e socialmente hoje Portugal, as famílias podem desempenhar um papel muito importante no apoio aos idosos "mas têm a sua ação limitada pelas suas próprias contingências e recursos", tendendo a estarem mesmo impossibilitadas da função de apoiar. Ainda assim, neste quadro socioeconómico-cultural, as próprias famílias esperam e exigem muito de si próprias, mas uma coisa é o que idealizaram e querem dar, e outra bem distinta será o que podem dar.

Independentemente dos posicionamentos, a problematização das relações entre família e políticas sociais reacendeu o interesse da investigação sobre redes de parentesco e solidariedades familiares e intergeracionais (Lesemann \& Martin, 1995; Martin, 2004).

\section{A provisão informal à população idosa em Portugal}

\section{O quadro de vulnerabilidade social da população idosa em Portugal e o contexto familiar}

As famílias, como unidade social básica que assume como principal função interna o assegurar da proteção e da promoção do desenvolvimento autónomo dos seus membros (Alarcão, 2015), são identificadas como as principais responsáveis pelo domínio assistencial e de cuidado às gerações mais jovens e mais velhas (Bazo, 2008; Figueiredo, 2007; Pimentel, 2015; Serapioni, 2005; Sousa, Figueiredo \& Cerqueira, 2004; Sousa \& Figueiredo, 2007; Williams, 2010;), sendo as últimas as focadas neste trabalho.

A Constituição da República Portuguesa reconhece a família como elemento fundamental da sociedade no seu artigo 67, consignando-Ihe direitos de proteção pelo Estado para efetivação de condições que permitam a realização pessoal dos seus 
membros, designadamente, no que concerne às gerações mais velhas, promovendo a sua independência social e económica, a criação de equipamentos sociais de apoio à família, a conciliação da atividade profissional com a vida familiar, no quadro de uma política global e integrada de família, nomeadamente, uma política de terceira idade. A definição genérica de uma política para as gerações com mais idade encontra os seus alicerces no artigo 72 que declara:

As pessoas idosas têm direito à segurança económica e a condições de habitação e convívio familiar e comunitário que respeitem a sua autonomia pessoal e evitem e superem o isolamento ou a marginalização social,

enunciando uma política de terceira idade que englobe

medidas de carácter económico, social e cultural tendentes a proporcionar às pessoas idosas oportunidades de realização pessoal, através de uma participação activa na vida da comunidade.

Consciente da relevância social cada vez maior da população idosa a nível mundial, a Organização das Nações Unidas consagra um conjunto de cinco princípios para o idoso que devem orientar a formulação de políticas sociais dos seus estados membros: independência, participação, assistência, autorrealização e dignidade. Relativamente à provisão social, para além dos direitos de cidadania, e do acesso a bens básicos e de assistência à saúde, estes princípios estabelecem o direito a "ter apoio familiar e comunitário" e de "poder viver em ambientes seguros adaptáveis à sua preferência pessoal", nomeadamente a "poder viver em sua casa pelo tempo que for viável", assim como beneficiar de "assistência e proteção da família e da comunidade" e de "meios apropriados de atenção institucional" com direito à "tomada de decisão quanto à assistência" (Resolução 46/91 de 16 de dezembro de 1991 da ONU - Princípios das Nações Unidas para o Idoso). Na mesma linha, a Carta dos Direitos Fundamentais da União Europeia, no artigo 25,

reconhece e respeita o direito das pessoas idosas a uma existência condigna e independente e à sua participação na vida social e cultural (Jornal Oficial da União Europeia, 83/392 de 30 Mar. 2010).

Tais direitos estão subjacentes à ideia de envelhecimento ativo defendida pela Organização Mundial de Saúde (WHO, 2002), entendido como processo de otimização das oportunidades para a saúde, participação e segurança, no sentido de melhorar a qualidade de vida das pessoas que envelhecem. A independência e a autonomia são fulcrais neste processo, ou seja, a capacidade para realizar funções da vida diária, e de viver na comunidade sem ajuda ou com pequena ajuda de outrem e a capa- 
cidade percebida para controlar, lidar com situações e tomar decisões sobre a sua vida, de acordo com as próprias regras e preferências (WHO, 2002). Reconhecendo a centralidade destas dimensões, o Ano Europeu para o Envelhecimento Ativo e Solidariedade entre Gerações, em 2012, foi proclamado pela União Europeia com a finalidade de contribuir para contrariar a ideia de que os idosos constituem um fardo para a sociedade, favorecendo o seu papel social ativo e condições para um envelhecer saudável e independente (Eurostat, 2011).

No entanto, a senescência nem sempre permite um envelhecimento ativo e autónomo. A Organização das Nações Unidas (UN, 2015: 78) reconhece que para largos segmentos da população, a idade avançada é associada a dependência e a vulnerabilidade crescentes relacionadas com o declínio do rendimento ou da saúde, havendo uma crescente necessidade de cuidado e suporte. Quando há perdas de independência e de autonomia torna-se especialmente relevante a solidariedade intergeracional (Nunes, 2015), particularmente a que implica trocas de sentido ascendente (Pimentel, 2015), das gerações mais novas para as mais velhas, colocando a proteção como responsabilidade substantiva do sistema familiar, dentro de um sistema de valores aceites pela sociedade e no respeito pela liberdade individual. Fernandes (2001) considera a velhice dependente como o grande desafio do início deste milénio, sendo que a sua intensificação e a diversidade de problemas associados à dependência coloca dificuldades aos sistemas de provisão social formais, apresentando-se os sistemas informais mais flexíveis para responder a tais exigências, exigindo-se um laço entre as solidariedades familiares e as políticas sociais, de acordo com a autora. Estima-se que o quadro futuro agudize este desafio para as famílias quando há dependência, sobretudo entre os mais velhos, pois a autonomia assegura aos idosos elevados níveis de participação social, constituindo-se como uma forte ajuda na vida familiar (OCDE, 2012).

Mas a vulnerabilidade social do grupo populacional dos idosos, que remete para um amplo conjunto de complexos determinantes sociais estruturais, conjunturais e individuais que se conjugam na exposição ao risco social, salvaguardando a sua heterogeneidade espelhada pelos cursos de vida e condições socioeconómicas, não se traduz apenas através de eventuais limitações na funcionalidade, mas também por via das perdas relacionais e do isolamento social, do corte com o mundo do trabalho e da diminuição da participação social, assim como de possíveis quebras financeiras.

Em Portugal, o índice de envelhecimento aumentou drasticamente de 27,3\% para 127,8\% em 51 anos (1960-2011), assim como o índice de longevidade de 33,6 para 47,9 , no mesmo período (Pordata, 2016). Este grupo populacional, cada vez mais relevante no conjunto da população, evidencia fortes níveis de perda de autonomia 
a partir dos 65, considerando os indicadores sobre incapacidades e a esperança média de vida com saúde (Eurostat, 2011). Portugal encontra-se alinhado com a média da esperança média de vida aos 65 anos registada na União Europeia (EU) no século XXI (Eurostat, 2011; Pordata, 2016), esperando os homens viverem mais 17,8 anos (EU-28: 17,9) e as mulheres 21,6 (EU-28: 21,3), em 2013 (Pordata, 2016). Porém, os indicadores portugueses encontravam-se francamente afastados da média para os países da UE relativamente ao número de anos de vida saudável expectável aos 65 anos até muito recentemente (Eurostat, 2011; Pordata, 2016), tendo progredido nos últimos dois anos em que os dados estão disponíveis (2012 e 2013; cf. Pordata, 2016), apesar de ser difícil estabelecer uma variação rigorosa atendendo a mudanças metodológicas no registo estatístico. No entanto, note-se que no período de cinco anos (entre 2008 e 2013) regista-se uma variação positiva de três anos para os homens e de 3,7 anos para as mulheres. Os dados portugueses de 2013 indicam 9,6 e 9,3 anos de vida saudável após os 65 anos de idade para homens e mulheres, respetivamente (Pordata, 2016), o que ultrapassa a média da UE em cerca de 1 ano, mas encontram-se ainda muito afastados dos valores registados na Islândia $(15,1$ anos para ambos os sexos), Noruega (Homens, 15,0; Mulheres, 14,8) ou Suécia (Homens, 12,9; Mulheres, 13,8). Isto é, um residente em Portugal tem probabilidade de viver menos um terço dos anos de vida saudáveis do que um residente na Islândia após completar 65 anos de idade, o que evidencia a necessidade de maior investimento em determinantes sociais da saúde e em políticas de saúde e de velhice no nosso país. Relativamente às incapacidades, segundo dados do Censo de 2011, 50\% da população com 65 ou mais anos refere ter dificuldade em pelo menos uma atividade funcional básica, tanto a nível sensorial, de mobilidade como de comunicação (ver, ouvir, andar, memória/concentração, tomar banho/vestir-se, compreender os outros/fazer-se entender) (INE, 2012), sendo apenas 4,4\% da população idosa a registar muitas dificuldades ou a não conseguir realizar qualquer das seis atividades. Tais dados confirmam a necessidade de atenção a este grupo populacional ante as dificuldades que apresenta, apesar da sua heterogeneidade e do facto da outra metade conseguir realizar todas as atividades sem dificuldade. Preocupação social que se redobra tendo em conta que mais de metade destas pessoas idosas vivem sozinhas ou acompanhadas exclusivamente por outros idosos, $22 \%$ e $35 \%$, respetivamente (INE, 2012). Destes idosos com pelo menos uma dificuldade, $36,1 \%$ vivem no contexto de agregados familiares constituídos por membros com idade inferior a 65 anos e 7,1\% vivem no contexto institucional, percentagem esta que mais do que dobra quando as pessoas apresentam dificuldades em tomar banho e vestir-se $(15,9 \%)$.

Ainda relativamente aos dados dos Censos de 2011 sobre as incapacidades, regista-se que a proporção da população com pelo menos uma incapacidade funcional 
aumenta progressivamente com o avançar da idade: se a taxa de incidência nos 6569 anos é de $31,2 \%$, nos 75-79 anos é de 53,5\%, nos $85-89$ é de $77,5 \%$ e de $85,5 \%$ nos 90 e mais anos. Se a maior longevidade aumenta a dependência, também o sexo é um determinante social relevante, apresentando as mulheres proporções médias superiores às dos homens em dez pontos percentuais, em todos os grupos etários (INE, 2012).

Apesar do progresso científico incomensurável registado nos séculos XX e XXI, o aumento da esperança média de vida aumenta a probabilidade de vivermos na idade avançada períodos mais longos de incapacidade e dependência, aumentando a primazia das doenças crónicas e degenerativas, assim como as polipatologias, nas causas de morbilidade, incapacidade e mortalidade à medida que se envelhece (Cabral, Silva \& Mendes, 2002; Machado, 2009; UN, 2015; WHO, 2002). Ao se considerar estes e outros indicadores associados, é admissível que muitas famílias venham a confrontar-se com situações de vulnerabilidade associadas à doença e à incapacidade por parte dos seus familiares idosos no curso da vida (Deus, Guadalupe \& Daniel, 2012). Ao se considerar a demografia, todas as estimativas apontam para que as dificuldades se agudizem, tomando em conta as mudanças nas famílias e nos sistemas de bem-estar.

Os idosos têm sido apontados como um grupo populacional vulnerável à pobreza e à exclusão social (Costa, 2004; Costa, Baptista, Perista, Carrilho, 2008; Farinha e Andrade, 2013; Lopes, 2015), apresentando, em Portugal, uma taxa de risco de pobreza de $90,3 \%$ antes de transferências sociais e de 17,1\% após as transferências, em 2014 (INE, 2015), sendo indicadores relevantes do enorme impacte da providência estatal, apesar dos limites da prevalecente abordagem monetarista que não deixa transparecer outros indicadores também importantes sobre as condições de vida (Lopes, 2015). Não obstante as taxas de risco de pobreza elevadas, note-se que tem havido uma evolução descendente desde o seu registo (Farinha e Andrade, 2013; INE, 2010, 2014, 2015), tendo vindo a baixar até 2012 para 14,6\%, mas registado um acréscimo em 2013 (15,1\%) e em 2014 (17,1\%), estando em 2014 abaixo da taxa de risco de pobreza para a população geral em 2,4 pontos percentuais (INE, 2015). A diminuição sustentada das taxas de pobreza na última década, em cerca 47\% entre 2005 e 2013 em Portugal refletem o investimento de medidas de política social centradas no acréscimo de rendimento neste segmento populacional, que assumiu centralidade nas agendas políticas a nível europeu, por um lado, e a renovação geracional, tendendo as novas gerações de idosos a serem menos vulneráveis economicamente, por outro (Lopes, 2015). Farinha e Andrade (2013) sublinham a heterogeneidade do fenómeno entre a população idosa, sendo os mais velhos e isolados, com 75 e mais anos a viverem sós, que apresentam as taxas de pobre- 
za mais elevadas, apresentando as mulheres um maior risco de pobreza quando comparadas com os homens (19,1\% vs. $14,4 \%$ em $2014 ; 19,3 \%$ vs. $17 \%$ na taxa de intensidade de pobreza, no mesmo ano) (INE, 2015). Aparentemente poderíamos sublinhar uma viragem na distribuição de rendimentos, ultrapassando-se a histórica desvantagem da população idosa, no entanto, uma leitura atenta mostra-nos que o efeito de retração mais acentuada nas taxas de pobreza se encontra ancorada no abaixamento do rendimento mediano e, consequentemente, da linha de referência da pobreza² (Lopes, 2015). Como esta população é muito dependente das transferências sociais e, por isso, com rendimento menos flutuante, uma percentagem significativa ficou acima de um limite agora abatido no cálculo do risco de pobreza ${ }^{3}$. As opções políticas austeras nos últimos anos em Portugal, refletiram-se numa quebra generalizada de rendimentos e no aumento da privação material, também no escalão etário com 65 ou mais anos, tendo sido, no entanto, o grupo populacional que viu menos agravada a quebra de rendimentos entre 2009 e 2014 (Rodrigues, Figueiras \& Junqueira, 2016). Continua, assim, a representar uma população de atenção, havendo que equacionar, segundo Lopes (2015), a sua pobreza na velhice como resultante de trajetórias de vulnerabilidade social ao longo da vida, com acumulação de desvantagens, agravadas geralmente com a passagem do tempo.

A composição dos agregados familiares evidenciam também mudanças e constitui um indicador relevante para a nossa análise. Aproximadamente $50 \%$ das famílias clássicas unipessoais são constituídas por pessoas com 65 anos ou mais (variando nos seguintes valores censitários: 51,9\% em 1981; 55,5\% em 1991; 50,8\% em 2001; 46,9\% em 2011), sendo que os valores estimados para os agregados domésticos privados unipessoais são superiores (62,2\% em 2001; 54,9\% em 2011) ${ }^{4}$ (Pordata, 2016). Estes agregados domésticos unipessoais de indivíduos com 65 e mais anos representavam 9,5\% e 10,6\% em 2001 e 2011, respetivamente, do total de agregados domésticos, tendo-se mantido estáveis as percentagens nos últimos dez anos, sendo a percentagem registada em Portugal menor comparativamente à média da União Europeia (EU-28), em aproximadamente dois pontos percentuais (Pordata, 2016). Por seu lado, o tamanho das famílias tem vindo a decrescer progressivamente, tendo diminuído, em média, um membro desde a segunda parte do século XX ( $M=3,7$ em 1960 e 1970; $M=2,6$ em 2011) (Pordata, 2016). Hoje é menos frequente a família grande (o número de famílias com seis ou mais membros tem vindo a decrescer substancialmente) e com múltiplas gerações, com maior proporção de idosos que vivem sós, o que evidencia maior autonomia destes, mas também maior isolamento em relação à família alargada (Fernandes, 2001). Ainda assim, apesar do aumento da probabilidade de existência de famílias multigeracionais, a coexistência de quatro ou mais gerações é rara e tendente a ser fugaz (Vicente \& Sousa, 2012).
2. Entende-se por limiar de risco de pobreza, ou linha de pobreza relativa, o correspondente a $60 \%$ do rendimento nacional mediano por adulto equivalente após transferências sociais (Cf. Metainformação - INE, Eurostat).

3. Note-se que, entre 2009 e 2014, no escalão etário 65+ anos verificou-se a redução da taxa de pobreza em 3,4 pontos percentuais, se usarmos como referência a linha de pobreza "oficial", mas esta situação reverte-se quando usamos a linha de pobreza ancorada em 2009, verificando-se um aumento de 3,3 pontos percentuais (Rodrigues, Figueiras \& Junqueira, 2016: 68-69).
4. Notem-se as diferenças nos conceitos e na metodologia. $\mathrm{O}$ Instituto Nacional de Estatística de Portugal (INE) considera famílias clássicas o "conjunto de pessoas que residem no mesmo alojamento e que têm relações de parentesco (de direito ou de facto) entre si, podendo ocupar a totalidade ou parte do alojamento. Considera-se também como família clássica qualquer pessoa independente que ocupe uma parte ou a totalidade de uma unidade de alojamento". 
(metainformação INE); e o agregado doméstico privado

"inclui quem partilha a casa e as principais despesas, podendo os indivíduos ter ou não laços familiares", incluindo as pessoas que vivem sozinhas; sendo também definido como o "conjunto de pessoas que residem no mesmo alojamento e cujas despesas fundamentais ou básicas (alimentação, alojamento) são suportadas em conjunto, independentemente da existência ou não de laços de parentesco; ou a pessoa que ocupa integralmente um alojamento ou que, partilhando-o com outros, não satisfaz a condição anterior". (metainformação INE).

\section{O papel das solidariedades informais}

face à vulnerabilidade social da população idosa

O papel dos laços informais na proteção assume também relevância pelo seu reverso, isto é, pela vulnerabilidade social na ausência de proteção. Robert Castel (2003) analisa as relações concretas de sociabilidade como um dos eixos principais - a par com o eixo do trabalho - do que considera o "novo aumento da vulnerabilidade social" ou a "reemergência da precariedade social" no quadro das ditas sociedades capitalistas avançadas. Na mesma linha de pensamento, Serge Paugam (2000; 2003) coloca o enfraquecimento dos laços sociais, marcado pela fragilização e instabilidade da estrutura e dos laços familiares, como uma das evoluções estruturais simultâneas da sociedade que se ligam à pobreza contemporânea, a par da degradação do mercado de emprego. Em sua análise, centrada em populações subsidiadas por medidas de política social e assistidas por serviços sociais, observa processos de desqualificação social que se associam ao que o autor designa por dessocialização (Paugam, 2000). O autor considera que os processos que colocam populações em esferas de inatividade e de assistência com riscos acumulados de dificuldade, geralmente na sequência de uma desclassificação ou de uma continuada não integração no mercado de trabalho, tendem a conduzir os indivíduos entre situações de fragilidade a situações de rutura. Estas ruturas fazem-se na relação aos sistemas básicos de inclusão social e de cidadania, fortemente interdependentes (Costa, 2004) sendo que a desafiliação se reporta particularmente à rutura com as "redes de integração primária", isto é um "desatrelamento" face à família e ao sistema de interdependências fundadas na pertença comunitária (Castel, 2003: 50), verificando-se risco de desafiliação quando

o conjunto das relações de proximidade que um indivíduo mantém a partir de sua inscrição territorial, que é também sua inscrição territorial familiar e social, é insuficiente para reproduzir sua existência e para assegurar sua proteção (Castel, 2003: 51).

Ao empregar a metáfora do plano inclinado com sucessivas ruturas para o processo de exclusão, no extremo temos a rutura dos laços familiares e afetivos (Costa, 2004), constituindo uma exclusão de tipo social com "privação de tipo relacional, caracterizada pelo isolamento, por vezes associada à falta de autossuficiência e autonomia pessoal" (Costa, 2004: 22), enquadrando-se aqui os exemplos da população idosa em situação de solidão associada ao isolamento e em situação de dependência.

Como referimos antes, nos sistemas de proteção social de natureza familista, a provisão pública é limitada, sendo que o bem-estar dos indivíduos depende sobretudo do suporte informal recebido da família (Grundy \& Tomassini, 2003: Saraceno, 
2010). Um estudo comparativo entre países com diferentes tradições de bem-estar e de provisão familiar, uns com tradição dita coletivista e outros individualista, focado no cuidado às pessoais mais velhas e nas relações intergeracionais (Daatland \& Lowenstein, 2005), faz notar que o avanço das políticas públicas nesta área nunca foi substitutiva do papel da família e da solidariedade intergeracional, mas garantiu maior autonomia entre gerações, ainda que no caso dos países com uma cobertura mais ampla de serviços, os cuidados exclusivamente familiares aos idosos sejam francamente mais reduzidos face aos cuidados de responsabilidade estatal e mistos (formais e informais). O contributo das solidariedades primárias face aos problemas colocados pelo envelhecimento populacional é enorme, tanto devido às flutuações nos modelos e políticas de bem-estar, como à pressão demográfica, às mudanças na repartição dos papéis na família e na comunidade e à retração da dimensão das famílias (Hespanha, 1993).

As tendências demográficas no padrão de envelhecimento, os indicadores sociais e a alteração das configurações familiares, associadas ao modelo moderno de família (Bris, 1994), tais como a diminuição da natalidade, das taxas de casamento com registo, do tamanho da família e do número de filhos, o adiamento da maternidade, o aumento dos divórcios, das famílias monoparentais e isoladas, a não coabitação intergeracional, entre outras, conjugam-se num quadro preditor de coexistência de mais gerações durante um maior número de anos. Este quadro, a que Bazo (2008: 75) alude como uma "revolução demográfica" produz diversificação nos modelos, estruturas e papéis intergeracionais. Nele teremos mais vínculos familiares verticais e intergeracionais (mais avós e bisavós) do que horizontais e intrageracionais (menos irmãos, tios e primos) (Bazo, 2008), assim como um maior número de pessoas para cuidar e de um menor número de potenciais cuidadores informais (Aguirre, 2008), o que coloca múltiplos desafios em múltiplos campos, nomeadamente nos das relações intergeracionais e das políticas sociais. Outras mudanças societais, designadamente o aumento da mobilidade geográfica, deslocalização e da participação da mulher no mercado de trabalho, assim como mudanças no mundo do trabalho que deixam menos tempo e condições para o exercício de outras atividades no quotidiano (Bris, 1994; Capucha, 2014; Vicente \& Sousa, 2012), agudizam tais desafios.

O debate sobre a articulação entre solidariedades familiares e solidariedades públicas tem sido atravessado pela questão da substituibilidade das políticas públicas pelo papel providencial das famílias, sendo esta contestada por autores como Attias-Donfut e Ogg (2009), Capucha (2014) ou Lesemann e Martin (1995), que as concebem com naturezas, motivações, regras, princípios, funções e finalidades distintas e, por isso, "lógicas e formas de solidariedade diferentes, não substituíveis" 
(Lesemann \& Martin, 1995: 125). Capucha (2014) defende mesmo que o Estado será a entidade com maior responsabilidade, e até melhor qualificada e colocada, para assegurar a qualidade de vida aos idosos, não podendo ser substituída pela solidariedade mecânica. Num estudo comparativo entre oito países, centrado na análise das políticas de cuidados aos idosos dependentes, Lesemann e Martin (1995) referem que prevalecem os modelos em que o apoio informal ultrapassa em muito o apoio formal. Isto não significa que um tenha um papel mais relevante que outro, ou se substituam, assumindo um papel complementar, nomeadamente em situação de dependência (Attias-Donfut \& Ogg, 2009).

Mas nem sempre os laços familiares existem, se encontram disponíveis, se encontram próximos, encaram a missão de apoiar ou cuidar como suas, conseguem conciliar a vida profissional com o cuidar, reúnem condições de vida, ou sequer equacionam mudanças para poderem apoiar as gerações mais velhas. Andrade (2009: 66) faz notar as contradições da dinâmica familiar, referindo metaforicamente que não podemos associar a família a uma "ilha de virtude em um grande mar de dificuldades", sendo que os laços familiares apresentam fragilidades e não apenas potencialidades, operando-se num quadro paradoxal e ambivalente (Gil, 2010). Se quase sempre associamos à família o que é positivo nas relações interpessoais (o afeto, o suporte, a entreajuda, a reciprocidade, a pertença etc.), podemos também encontrar manifestações de conflito, desprezo, agressividade, tensão, negligência e maus-tratos no seio familiar (Gil, 2010; Gil, Santos, Kislaya \& Nicolau, 2014; Simeone, 1990 apud Lesemann \& Martin, 1995). Apesar disso, no contexto cultural português, é no parentesco que encontramos laços fortes, mesmo quando há conflito relacional (Portugal, 2011). Segundo Luísa Pimentel (2012; 2015) as dimensões negativas na família são mobilizadoras da atenção pública, escamoteando-se muitas vezes as razões que subjazem ao risco ou ao perigo, e colocando-se na sombra o suporte familiar eficaz e bem-sucedido, preterido pela ausência de espetacularidade e pela assunção do cuidar como dever moral, difundindo mitos de negligência e abandono generalizados, de descomprometimento e rutura, contrariados na vida e ação quotidiana.

Todavia, a família continua a ser valorizada e entendida genericamente como "o lugar primordial das trocas intergeracionais" (Fernandes, 2001: 48; Bazo, 2008). Os estudos desenvolvidos por Sílvia Portugal $(2011 ; 2014)$ sublinham a centralidade da família nas redes de suporte social na sociedade portuguesa, pois

é nos laços familiares que a maioria das pessoas encontra resposta para as suas necessidades de apoio material e afectivo (Portugal, 2011: 41), 
fazendo coincidir a rede de suporte com a rede de parentesco (Vasconcelos, 2005). Os laços familiares assumem uma representação social como "aqueles com que podemos contar", associando-os à proteção e segurança, ideia que se funda na perenidade das relações e que "resulta de um entrecruzar de vínculos biológicos, emocionais, sociais e jurídicos, socialmente construídos" (Portugal, 2011: 41). Como antes referimos, no contexto atual de amplificação do neoliberalismo, há um

quadro de apelo, mais ou menos explícito, dos poderes públicos ao suporte familiar, e à sua (pretensa) eficácia, para concretizar missões que o Estado por si só não pode, ou não quer, concretizar (Pimentel \& Albuquerque, 2010: 25),

particularmente no caso do apoio às pessoas idosas com incapacidades. Pimentel e Albuquerque (2010, p. 25) sublinham que

o suporte aos membros da família mais desprotegidos corresponderia, aliás, de acordo com determinados movimentos familiares de cariz mais conservador, à essência axiológica e cultural da própria família, fortemente ancorada no dom-de-si e na reciprocidade afectiva e material (Pimentel e Albuquerque \& 2010: 25).

A norma da reciprocidade na dádiva familiar estende-se temporalmente na cadeia que atravessa gerações ao longo da história da família, pelo que cuidar dos pais na velhice é uma forma de retribuição pelas dádivas recebidas e pelos mais velhos agora terem antes cuidado dos mais novos e dos mais velhos (Attias-Doufut, Lapierre \& Segalen, 2002; Portugal, 2011). Dádiva e dívida estão intimamente associadas (Prier, 1999), mas o tempo modifica a posição de recetor e de dador do suporte. Transgeracionalmente, numa expectativa de retribuição simétrica, este contrato latente e implícito de reciprocidade ganha contornos concretos ou concretizáveis quando os pais envelhecem e necessitam de ver compensada a diminuição eventual de sua autonomia, sendo uma das circunstâncias na vida em que se reafirma a norma da reciprocidade (Grundy, 2005; Portugal, 2011) ou de dívida positiva, concebida como um gesto de dar sem que o donatário coloque o outro numa posição de devedor (Godbout, 2000). O membro da família que recebe apoio pode querer evitar sentir-se dependente ou intentar ações para compensar com apoio de outra natureza, favorecendo uma relação mais simétrica (Parrott \& Bengtson, 1999). Para além disso, nem o suporte entre gerações ocorre simetricamente entre todos os membros das famílias nem se verifica como constante ao longo do curso de vida, assumindo também diferentes formas (Fernandes, 2001) e nem sempre as expectativas face ao cuidar coincidem entre pais e filhos (Bazo, 2008). As generalizações, não são, assim, possíveis. 
A reciprocidade e a dádiva emergem sempre como componentes analíticas na provisão informal entre gerações. Afirma Sílvia Portugal (2011, p.50; 2014) que

a dádiva cria um vínculo social de solidariedade selectiva, construída com base em princípios de afectividade e afinidade, que se encontram em permanente construção e reconstrução (Portugal, 2011: 50).

Na mesma linha de ideias, Attias-Donfut (1998) identifica o laço de reciprocidade, com base na dívida associada a dádivas passadas, entre as ordens de motivação para a entreajuda intergeracional. A chamada teoria do intercâmbio, baseada na ideia de reciprocidade associada à solidariedade entre gerações é uma das perspetivas teóricas na abordagem às expectativas sobre o cuidar intergeracional, para além das teorias do papel (de género e na relação parental-filial) baseadas na aculturação e nas teorias da vinculação, ou o interacionismo simbólico na abordagem à construção social dos significados da obrigação de cuidar (Bazo, 2008). Neste debate cruzam-se determinantes sociais e culturais sobre as responsabilidades familiares e sobre os afetos (Gil, 2010).

No entanto, o dever da família, no caso português, não é apenas moral mas também legal, assim como na generalidade dos países da OCDE (OCDE, 2012). O Código Civil (Lei n. 150/2015, de 10 de setembro de 2015) reconhece no seu artigo n.ㅇ 2.009 o direito a alimentos também a ascendentes (isto é, "tudo o que é indispensável ao sustento, habitação e vestuário", artigo n.․ 2003). Em 2015, foi definida uma Estratégia de Proteção ao Idoso (cf. Resolução do Conselho de Ministros n.ำ 63/2015 de 25 de agosto de 2015) que vem propor um conjunto de alterações a ponderar nos Códigos Civil e Penal. Neste documento chama-se a atenção para as especificidades associadas à idade avançada "designadamente no plano dos cuidados de saúde, do apoio social e do enquadramento familiar, bem como da tutela jurídica" defendendo-se a sua regulamentação no sentido de reforçar os seus direitos de proteção, particularmente das pessoas com incapacidades. Este enunciado de princípios, da iniciativa do XII Governo Constitucional, parece entrar, no entanto, em contradição com a sua ação governamental que retirou proteção às famílias e aos cidadãos visados, como antes referimos. Mais recentemente, as Resoluções da Assembleia da República n. 129/2016 e n. 130/2016, de 18 de julho de 2016, recomendam, respetivamente, ao governo português a criação do estatuto do cuidador informal, inscrevendo direitos e garantias específicos, bem como de medidas de apoio aos cuidadores informais, que definam um modelo prestacional de solidariedade informal.

Lesemann e Martin (1995) referem que, no contexto da crise dos sistemas públicos providenciais, assistimos a um interesse pelo papel real e potencial das solidarieda- 
des familiares e informais, havendo um reforço no reconhecimento do contributo dos recursos primários no que designam por "proteção próxima", entendida como simples, flexível, vantajosa e eficaz como recurso na satisfação de necessidades da população idosa a diversos níveis (de alojamento, de saúde, de reabilitação, de inserção, de socialização, entre outras). Caldas (2003) reforça esta ideia, afirmando que,

com a falência do sistema previdenciário, a família vem progressivamente se tornando a única fonte de recursos disponível para o cuidado do idoso dependente (Caldas, 2003: 774).

Ainda que não em exclusividade, e apesar dos argumentos pessimistas sobre o dever de cuidar das pessoas idosas dependentes (Bazo, 2008), acusando as famílias de desresponsabilização (Pimentel, 2015), a evidência parece apontar para a persistência das famílias como o pilar dos cuidados, mesmo em países onde o sistema formal de bem-estar proporciona amplos serviços e apoios para as pessoas idosas (Bazo, 2008; Bris, 1994; Daatland \& Lowenstein, 2005; Gil, 2010; Pimentel, 2015; Serapioni, 2005; Sousa \& Figueiredo, 2004).

Já no caso de idosos dependentes e isolados socialmente, que apresentam vulnerabilidade acrescida e progressiva (Castel, 2003; Conselho Económico e Social, 2013), a situação é distinta, porque aumentada em exigência. Apesar da ancoragem familiar dos cuidados, Luísa Pimentel (2015: 176) faz notar que "nunca as famílias tiveram tantos dos seus elementos idosos a necessitar de cuidados e jamais por períodos tão longos", encontrando um conjunto de incapacidades e de dificuldades acrescidas para as quais necessita de compensação efetiva. Acrescente-se que a trajetória da dependência obriga a uma trajetória de cuidados (Corbin, 1992apud Gil, 2010), dinâmica e evolutiva, com variações nas relações intersistémicas e nas necessidades de quem é cuidado e de quem cuida.

A eficácia seguradora das redes em mobilizar recursos de apoio ao longo da vida ativa dos indivíduos é confinada, nas situações de dependência, a poucas pessoas que assumem os cuidados e a responsabilidade pelo bem-estar, sobretudo as muIheres da rede de parentesco - esposas, filhas ou noras (Lesemann \& Martin, 1995; Aguierre, 2008; Conselho Económico e Social, 2013; Pimentel, 2011; Gil, 1999). Por isso, o aprofundamento do processo de refamilização compelido pelos impactes da opção política pelas medidas de austeridade implementadas em Portugal desde 2011, tem particularmente reflexos entre as mulheres (Ferreira \& Monteiro, 2015).

A resolução que institui os Princípios das Nações Unidas para as Pessoas Idosas reconhece que 
5. Cf. Resolução n.ㅇ 46/91, de 16 de dezembro de 1991 da ONU. que as dificuldades da vida familiar nos países desenvolvidos e em desenvolvimento exigem que os que prestam assistência às pessoas idosas frágeis recebam apoio ${ }^{5}$.

Este apoio tem sido, no contexto social português, inconsistente e fragmentado, tanto na esfera das políticas públicas sociais e de saúde, como das respostas sociais, esmagadoramente do sector solidário, dificultando sobremaneira ou impossibilitando a conciliação do cuidado informal com a vida profissional ou a opção de dedicação ao cuidar, por exemplo (Gil, 2009). Ainda que com um crescimento substancial no número e investimento em equipamentos sociais nas últimas duas décadas (Joaquim, 2015), as taxas de cobertura destas respostas apresentam-se como insuficientes e irregulares territorialmente (Daniel, Monteiro \& Ferreira, 2016; Pimentel, 2008; 2015). As respostas sociais formais constituem um importante recurso para os idosos mais dependentes, com ou sem inserção familiar, e encontram apoio para o seu acompanhamento, tanto em respostas diurnas, domiciliárias como residenciais. No entanto, apesar das relações entre o apoio formal e o informal se assumirem como complementares ou de substituição (MTSS, 2009), os cuidados às pessoas idosas são prestados sobretudo no contexto informal (Gil, 2009; 2010; Pimentel, 2012), sendo as respostas formais ainda pouco diversas e pouco flexíveis (Gil, 2009). Moody (2009 apud Pimentel, 2012) entende que os serviços formais deverão ser complementares ao apoio informal, servindo para o suportar e não para o substituir, no entanto nem sempre verificamos a exequibilidade desta asserção, e nem podemos salvaguardar a complementaridade ou exigir que a substituibilidade não aconteça.

Se as marcas da vulnerabilidade são heterogéneas, configurando-se singularmente na vida das pessoas, também diversas são e têm de ser as formas de enfrentá-las em sociedade, sendo múltiplos os desafios que tal coloca aos domínios da investigação, da intervenção social e da decisão política.

\section{Nota conclusiva}

Quando emergem dificuldades no sistema de proteção mais próximo, Castel (2003: 51) faz notar que "a sociabilidade primária é menos rompida do que distendida", sendo particularmente mais dinâmica, maleável e elástica do que os sistemas formais de provisão. Estas características têm possibilitado edificar soluções face à vulnerabilidade e à necessidade de cuidar, mesmo "quando tudo parece apontar em sentido contrário e quando todas as condições se conjugam para inviabilizar esses cuidados" (Pimentel, 2012: 68). Aqui o "tudo" se refere ao contexto demográfico, às mudanças nas estruturas familiares e à forma como vivemos em so- 
ciedade contemporaneamente, constituindo um fervoroso e permanente desafio. Mas a elasticidade dos sistemas familiares não é infinita, sendo que, em situação de sobrecarga pode desequilibrar-se e romper-se. Uma das situações que coloca à prova esta elasticidade é a vulnerabilidade social da população idosa, particularmente os níveis de dependência, que se apresentam com índices elevados na população portuguesa. A complementaridade triangular na provisão social com outros membros da rede de suporte informal, extrafamiliares, ou com serviços da rede secundária, e uma provisão pública que garanta o bem-estar dos idosos e das famílias, podem criar condições para a manutenção dessas competências e aliviar sobrecarga, evitando ruturas.

A avaliação das características das redes de suporte informais, assim como da sua capacidade e das condições efetivas para prover apoio em condições favorecedoras do bem-estar dos envolvidos é fulcral no diagnóstico social em serviço social, particularmente. A avaliação e a investigação que decorrer de sua sistematização colocará em evidência as potencialidades e as necessidades destes sistemas sociais, assim como as paradoxalidades desta equação compensatória assente no pilar das solidariedades familiares, numa relação desequilibrada com a intervenção de responsabilidade pública. Num contexto de opções políticas austeras, que retraem fortemente a provisão pública, esta equação torna-se ainda mais instável, tendente a sobrecarregar a responsabilidade informal, e, por isso, a favorecer a disrupção.

Apesar da diligência das famílias provedoras, são múltiplos e variados os problemas que se colocam perante a necessidade de proteção da vulnerabilidade, não só à pessoa idosa como às famílias e redes de suporte social informais, particularmente aos cuidadores obreiros de trabalho invisível, num plano microssocial, mas também aos profissionais, aos serviços, às organizações empregadoras, às comunidades, à população idosa, à população adulta (geralmente trabalhadora) e às gerações mais jovens, em suma, a toda a sociedade. O envelhecimento, populacional e individual, coloca desafios vultuosos que, a não serem equacionados, produzem negligência social grosseira, resultantes em problemas sociais que se refletem na vida das pessoas.

Este é um nível de interferência de responsabilidade profissional mas sobretudo coletiva, como tal, também estatal. A exigência dos cidadãos tem de fazer romper o silêncio para proporcionar medidas de política social capazes de proteger as pessoas idosas da vulnerabilidade social e garantir maior bem-estar coletivo, impondo que a malha de laços informais estique apenas até onde permita e queira ser esticada, sem romper. 


\title{
The informal social support networks as sources of social provision in Portugal: the case of elderly population
}

\begin{abstract}
Aging indicators in the Portuguese population, places Portugal as one of the most aged countries in the world, being the elderly a socially vulnerable group. The vulnerability, resulting from lifelong trajectories of progressive accumulation of disadvantages, has as determinants the strong levels of loss of autonomy with advancing age, the risk of social isolation and the high risk of social exclusion and poverty, compensated by the strong impact of social transfers on income, together with the changes in Portuguese society, particularly in the morphology of families and in labor. This vulnerability framework has been adressed with the expansion of welfare public policies, but also trough informal provision, especially by families. In more recent times, we witnessed a reversal in the providencial trajectory by the Portuguese state, increasingly retreated, accentuating the family responsibility.
\end{abstract}

The article presents a reflection on the relevance of informal social support in social welfare in Portugal regarding the elderly population, particularly problematizing the providential role of families in an austerity context, based on documentation and literature produced in and about the Portuguese social context.

Keywords: informal social provision; Welfare State, family, elderly, aging.

\section{Referências}

ABOIM, S.; VASCONCELOS, P.; WALL, K. Support, social networks and the family in Portugal: two decades of research. International Review of Sociology, v. 23 n. 1, p. 47-67, 2013.

AGUIRRE, R. El Futuro del cuidado. In ARRIAGADA, I. (Ed.). Futuro para las familias y desafíos para las políticas. Serie "Seminarios y Conferencias". Santiago de Chile: Cepal, 2008.

ALARCÃO, M. Família e sistemas envolventes. In FERNANDES; O. M.; MAIA, C. (Coords.). A família portuguesa no século XXI. Lisboa: Parsifal, 2015.

ANDRADE, F. F. Desfamiliarização das políticas sociais na América Latina: uma breve análise dos sistemas de proteção social na região. Barbarói, v. 31, p. 56-71, 2009.

ATTIAS-DONFUT, C. La dynamique de l'entraide intergénérationelle. In: Age, génération, activité: vers un nouveau contrat social? Actes des 1ères Rencontres Sauvy Paris: Caisse Nationale des Allocations Familiales, 14-15 Oct. 1998.

ATTIAS-DONFUT, C.; OGG, J. Évolution des transferts intergénérationnels: vers un modèle européen? Retraite et Société, n. 58, p. 11-29, 2009.

ATTIAS-DONFUT, C.; LAPIERRE, N.; SEGALEN, M. Le nouvel esprit de famille. Paris: Odile Jacob, 2002. 
BALANDIER, G. Sens et puissance. Paris: Presses Universitaires de France, 1986.

BAZO, M. T. Personas mayores y solidaridad familiar. Política y Sociedad, v. 45, n. 2, p. 73-85, 2008.

BOURDIEU P. À propos de la famille comme catégorie réalisée. Actes de la Recherche en Sciences Sociales, n. 100, p. 32-36, 1993.

BRANCO, F.; AMARO, I. As práticas do "Serviço Social activo" no âmbito das novas tendências da política social: uma perspectiva portuguesa. Serviço Social \& Sociedade, n. 108, p. 656-679, 2011.

BRIS, H. J-L. Responsabilidade familiar pelos dependentes idosos nos países das comunidades europeias. Lisboa: Conselho Económico e Social, 1994. Disponível em: <http://www.ces.pt/download/600/RespFamDepldosos.pdf>.

CABRAL, M. V.; SILVA, P. A.; MENDES, H. Saúde e doença em Portugal. Lisboa: Imprensa de Ciências Sociais, 2002.

CALDAS, C. P. Envelhecimento com dependência: responsabilidades e demandas da família. Cadernos de Saúde Pública, v. 19, n. 3, p. 773-781, 2003.

CAMPOS, M. S.; MIOTO, R. C. T. Política de assistência social e a posição da família na política social brasileira. Ser Social, v. 12, p. 165-190, 2003.

CAPUCHA, L. Envelhecimento e políticas sociais em tempos de crise. Sociologia, Problemas e Práticas, n. 74, p. 113-131, 2014.

CARVALHO, M. C. B. Famílias e políticas públicas. In: ACOSTA, A. R.; VITALE, M. A. F. (Orgs.). Família - redes, laços e políticas públicas. 5. ed. p. 267-275. São Paulo: Cedpe; PUC-SP; Cortez, 2010.

CARVALHO. I. M. M.; ALMEIDA, P. H. Família e proteção social. São Paulo em Perspectiva, v. 17, n. 2, p. 109-122, 2003.

CASTEL, R. As metamorfoses da questão social: uma crônica do salário. 4. ed. Petrópolis: Vozes, 2003 [1995].

L'État-providence et la famille: la gestion précaire des risques sociaux. In: SINGLY, François de; SCHULTHEIS, Franz (Éds.). Affaires de famille, affaires d'Etat, Actes du colloque franco-allemand "Sociologie de la famille". Jarville-La-Malgrange: Edition de L’Est, 1991. 
CASTILHO, C. F. V.; CARLOTO, C. M. O familismo na política de Assistência Social: um reforço à desigualdade de gênero? Anais do I Simpósio sobre Estudos de Gênero e Políticas Públicas. Londrina: Universidade Estadual de Londrina, 2010.

CONSELHO ECONÓMICO E SOCIAL. Parecer de Iniciativa sobre as consequências económicas, sociais e organizacionais decorrentes do envelhecimento da população. Lisboa: Conselho Económico e Social, 2013. Disponível em: <http://www.ces.pt/download/1335/FINAL_Parecer\%20Envelhecimento_aprovado\%20em\%20Plenario. $p d f>$.

COSTA, A. B. Exclusões sociais. Lisboa: Gradiva, 2004.

COSTA, A. B.; BAPTISTA, I.; PERISTA, P.; CARRILHO, P. Um olhar sobre a pobreza. Vulnerabilidade e exclusão social no Portugal contemporâneo. Lisboa: Gradiva, 2008.

DAATLAND, S. O.; LOWENSTEIN, A. Intergenerational solidarity and the Family-Welfare State balance. European Journal of Ageing, v. 2, p. 174-182, 2005.

DANIEL, F.; MONTEIRO, R.; FERREIRA, J. Cartografia da oferta pública e privada de serviços dirigidos à população idosa em Portugal. Serviço Social \& Sociedade, n. 126, p. 235-261, 2016.

DEUS, A.; GUADALUPE, S.; DANIEL, F. Expectativas associadas ao cuidar das gerações mais velhas: comparação entre filhos únicos e membros de fratrias. In: Livro de Actas do VII Congresso Português de Sociologia, Sociedade, Crise e Reconfigurações. Porto: Universidade do Porto (Portugal), 20 a 23 de Junho de 2012. Disponível em: <http://www.aps.pt/vii_congresso/papers/finais/PAP1067_ed.pdf>.

DUVOUX, N. Le nouvel âge de la solidarité - pauvreté, précarité et politiques publiques. Paris: Le Seuil-La République des idées, 2012.

ERERA, P. I. Family diversity. Continuity and change in the contemporary family. Thousand Oaks: Sage Publications, 2002.

ESPING-ANDERSEN, G. Social foundations of postindustrial economies. Oxford (UK): Oxford University Press, 1999. Press, 1990.

ESTEVES, A. J. A família numa sociedade em mudança. Sociologia, v. 1, n. 1, p. 79100, 1991. 
EUROSTAT. Active ageing and solidarity between generations - a statistical portrait of the European Union 2012. Luxembourg: Publications Office of the European Union, 2011. Disponível em: <http://epp.eurostat.ec.europa.eu/cache/ITY_OFFPUB/KS-EP-11-001/EN/KS-EP-11-001-EN.PDF>.

FARINHA, C.; ANDRADE, I. The age-old problem of old age poverty in Portugal. Lisbon: School of Economics \& Management, Centre for Applied Mathematics and Economics, University of Lisbon, 2013.

FERNANDES, A. A. Velhice, solidariedades familiares e política social: itinerário de pesquisa em torno do aumento da esperança de vida. Sociologia, Problemas e Práticas, n. 36, p. 39-52, 2001.

FERREIRA, A.; MORAES, V.; BADARÓ, L.; FRANCO, A. Família, protecção social e redes sociais: algumas reflexões a partir da história de vida de uma família. In: VIANNA A.; LACERDA, P. Direitos e políticas sexuais no Brasil: o panorama atual. Rio de Janeiro: Cepesc, 2004.

FERREIRA, V.; MONTEIRO, R. Austeridade, emprego e regime de bem-estar social em Portugal: em processo de refamilização? Ex aequo, n. 32, p. 49-67, 2015.

FERRERA, M. O futuro da Europa social: repensar o trabalho e a protecção social na nova economia. Lisboa: Celta, Presidência Portuguesa da União Europeia, 2000.

FIGUEIREDO, D. Cuidados familiares ao idoso dependente. Lisboa: Climepsi Editores, 2007.

FLANDRIN, J.-L. Famílias - parentesco, casa e sexualidade na sociedade antiga. Lisboa: Editorial Estampa, 1995.

FRADE, C.; COELHO, L. Surviving the crisis and austerity: the coping strategies of Portuguese households. Indiana Journal of Global Legal Studies, v. 22, n. 2, p. 631664, 2015.

FRANZONI, J. M. Regímenes del bienestar en América Latina. Madrid: Fundación Carolina, 2007. Disponível em: <http://www.fundacioncarolina.es/wp-content/ uploads/2014/08/DT11.pdf>.

GIL, A. P. M. Heróis do quotidiano: dinâmicas familiares na dependência. Lisboa: Fundação Calouste Gulbenkian; Fundação para a Ciência e Tecnologia, 2010. 
- Conciliação entre vida Profissional e vida familiar: o caso da dependência. Lisboa: Núcleo de Estudos e Conhecimento, Instituto de Segurança Social, 2009. Disponível em: <http://www.seg-social.pt/documents/10152/135827/conciliacao_ vida_profissional_familiar/2d308149-a66d-4075-bbaa-2eb95869c677>.

- Redes de solidariedade intergeracionais na velhice. Cadernos de Política Social, n. 1, p. 93-114, 1999.

GIL, A. P. M. (Ed.); SANTOS, A. J.; KISLAYA, I.; NICOLAU, R. Envelhecimento e violência. Lisboa: Instituto Nacional de Saúde Dr. Ricardo Jorge, 2014. Disponível em: <http://repositorio.insa.pt/bitstream/10400.18/1955/3/Envelhecimento\%20e\%20 Viol\%C3\%AAncia\%202011-2014\%20.pdf>.

GOdBOUT, J. T. Le don, la dette et l'identité. Paris: La Découverte, 2000.

GRUNDY, E. Reciprocity in relationships: socio-economic and health influences on intergenerational exchanges between Third Age parents and their adult children in Great Britain. British Journal of Sociology, v. 56, n. 2, p. 233-255, 2005.

GRUNDY, E.; TOMASSINI, C. El apoyo familiar de las personas de edad, en Europa: contrastes e implicaciones. Notas de Población, n. 77, p. 219-250, 2003.

GUERRERO, T. J.; NALDINI, M. Democratización de la familia y cambios demográficos en Espanha. In: GUERRERO, T. J. (Ed.). Cambios familiares y trabajo social, p.6593. Madrid: Ediciones Académicas, 2007.

HESPANHA, P. Vers une société-providence simultanément pré et post-moderne. Oficina do Centro de Estudos Sociais, n. 38. Coimbra: Centro de Estudos Sociais, 1993.

HESPANHA, P.; FERREIRA, S.; PACHECO, V. O Estado social, crise e reformas. In: OBSERVATÓRIO DAS CRISES E DAS ALTERNATIVAS (Org.). Anatomia da crise: identificar os problemas para construir alternativas, p. 161-249. Coimbra: Centro de Estudos Sociais, 2013.

INSTITUTO NACIONAL DE ESTATÍSTICA (INE, PORTUGAL). Rendimento e condições de vida, 2015 (Dados provisórios). Destaque. Lisboa: Instituto Nacional de Estatística, IP, 2015.

_. Dia Mundial da População, 11 julho de 2014. Destaque. Lisboa: Instituto Nacional de Estatística, IP, 2014.

—. Saúde e incapacidades em Portugal 2011. Lisboa: Instituto Nacional de Estatística, IP, 2012. 
- Sobre a pobreza, as desigualdades e a privação material em Portugal. Lisboa: Instituto Nacional de Estatística, IP, 2010.

JESUS, A. C. S.; AZEVÊDO, J. K. F.; SILVA, L. G. A participação da família na política social brasileira: construindo um campo de debates". Actas da V Jornada Internacional de Políticas Públicas. São Luís: Universidade Federal do Maranhão, 23 a 26 de Ago. 2011.

JOAQUIM, C. Proteção social, terceiro setor e equipamentos sociais: Que modelo para Portugal? Cadernos do Observatório. Coimbra: Observatório das Crises e Alternativas do Centro de Estudos Sociais, 2015. Disponível em: <http://www.ces.uc.pt/ observatorios/crisalt/documentos/cadernos/CadernoObserv_III_fevereiro2015. pdf>.

LEANDRO, M. E. Laços familiares em questão: antinomias nas sociedades hipermodernas. In LEANDRO, M. E. (Coord.). Laços familiares e sociais, p. 95-115. Viseu: Psicosoma, 2011.

LEANDRO, M. E.; FERREIRA, L. M. Os laços sociais em questão. Metamorfoses sociais, metamorfoses de uma nação. In LEANDRO, M. E. (Coord.). Laços familiares e sociais, p. 27-57. Viseu: Psicossoma, 2011.

LESEMANN, F.; MARTIN, C. Estado, comunidade e família face à dependência dos idosos. Ao encontro de um "Welfare-Mix"". Sociologia, Problemas e Práticas, n. 17, p. 115-139, 1995.

LOPES, A. Pobres que envelhecem ou velhos que empobrecem? - Alguns apontamentos sobre o tema da pobreza na população idosa. In: DIOGO, F.; CASTRO A.; PERISTA, P. (Orgs.). Pobreza e exclusão social em Portugal: contextos transformações e estudos, p. 149-164. V. N. Famalicão: Húmus, 2015.

MACHADO, M. C. Envelhecimento e políticas de saúde. In: FUNDAÇÃO CALOUSTE GULBENKIAN (Ed.). O tempo da vida, p. 125-133. Cascais: Princípia, 2009.

MARQUES, J. A reconfiguração do estado-providência. Gestão e Desenvolvimento, n. 15-16, p. 105-119, 2008.

MARTIN, C. The rediscovery of family solidarity: backgrounds and concepts? In: KNIJN, T.; KOMTER, A. (Eds.). Solidarity between the sexes and the generations: transformations in Europe, p. 3-17. Cheltenham: Edward Elgar, 2004.

— - Os limites da protecção da família - introdução a uma discussão sobre as novas solidariedades na relação família-Estado. Revista Crítica de Ciências Sociais, n. 42, p. 53-76, 1995. 
MINISTÉRIO DO TRABALHO E DA SOLIDARIEDADE SOCIAL (MTSS). A dependência: o apoio informal, a rede de serviços e equipamentos e os cuidados continuados integrados. Lisboa: Centro de Informação e Documentação (GEP-CID) do Ministério do Trabalho e da Solidariedade Social, 2009.

MIOTO, R. C. T. Família e políticas sociais. In: BOSCHETTI, I.; BEHRING, E.; MIOTO, R. C. T.; SANTOS, S. M. M. (Orgs.). Política social no capitalismo: tendências contemporâneas, p.130-148. São Paulo: Cortez, 2008.

NUNES, J. A. Com mal ou com bem, aos teus te atém: as solidariedades primárias e os limites da sociedade providência. Revista Crítica de Ciências Sociais, n. 42, p. 5-25, 1995.

NUNES, R. Ética e família. In: FERNANDES, O. M.; MAIA, C. (Coords.). A família portuguesa no século XXI, p. 39-50. Lisboa: Parfisal, 2015.

ORGANIZAÇÃO PARA A COOPERAÇÃO E DESENVOLVIMENTO ECONÓMICO (OCDE/OECD). The future of families to 2030. OECD Publishing, 2012.

PARROTT, T. M.; BENGTSON, V. L. The effects of earlier intergenerational affection, normative expectations, and family conflict on contemporary exchange of help and support. Research on Aging, v. 21, n. 1, p. 73-105, 1999.

PAUGAM, S. Le lien social. 2. ed. Paris: Presses Universitaires de France, 2009. 2003

A desqualificação social: ensaio sobre a nova pobreza. Porto: Porto Editora,

. A desqualificação social. In: SOULET, M.-H. (Org.). Da não-integração, p. 107-135. Coimbra: Quarteto, 2000.

PEDROSO, J.; BRANCO, P. Mudam-se os tempos, muda-se a família. As mutações do acesso ao direito e à justiça de família e das crianças em Portugal. Revista Crítica de Ciências Sociais, n. 82, p. 53-83, 2008.

PEREIRA, P. A. P. Mudanças estruturais, política social e papel da família: crítica ao pluralismo de bem-estar. In MIONE, A.; MATOS, M. C.; LEAL, M. C. (Orgs.). Política social, família e juventude: uma questão de direitos. 2. ed. p. 25-42. São Paulo: Cortez, 2006.

PICHLER, F.; WALLACE, C. Patterns of formal and informal social capital in Europe. European Sociological Review, v. 23 n. 4, p. 423-435, 2007. 
PIMENTEL, L. As pessoas idosas e os seus contextos familiares: convite a um olhar diferente. In: FERNANDES, O. M.; MAIA, C. (Coords.). A Família portuguesa no século XXI, p. 171-178. Lisboa: Parfisal, 2015.

Cuidar de pessoas idosas dependentes: as interseções entre a esfera pública e a esfera privada. Rediteia, n. 45, p. 67-77, 2012.

- O Sexo dos Anjos: os cuidados às pessoas idosas dependentes como uma esfera de acção preferencialmente feminina. Ex Aequo, n. 23, p. 23-37, 2011.

- Entre o dever e os afectos: os dilemas de cuidar de pessoas idosas em contexto familiar. Actas do VI Congresso Português de Sociologia, Mundos Sociais: saberes e práticas. Lisboa: FCSH da Universidade Nova de Lisboa, p. 1-15, 2008. Disponível em: <http://www.aps.pt/vicongresso/pdfs/259.pdf>.

PIMENTEL, L. G.; ALBUQUERQUE, C. P. Solidariedades familiares e o apoio a idosos. Limites e implicações. Textos \& Contextos, v. 9 n. 2, p. 251-263, 2010.

PORDATA - BASE DE DADOS DE PORTUGAL CONTEMPORÂNEO [on-line]. Censos da população em Portugal; Indicadores de envelhecimento em Portugal e na Europa; Famílias em Portugal e na Europa. PORDATA - Estatísticas, gráficos e indicadores de Municípios, Portugal e Europa. Lisboa: Fundação Francisco Manuel dos Santos, 2016.

PORTUGAL, S. Famílias e redes sociais. Ligações fortes na produção de bem-estar. Coimbra: Almedina, 2014.

. Dádiva, família e redes sociais. In: PORTUGAL, S.; MARTINS, P. H. (Orgs.). Cidadania, políticas públicas e redes sociais, p. 39-53. Coimbra: Imprensa da Universidade de Coimbra, 2011.

- Retórica e acção governativa na área das políticas de família desde 1974. Revista Crítica de Ciências Sociais, n. 56, p. 81-98, 2000.

PRIER, B. (Coord.). As heranças familiares. Lisboa: Climepsi, 1999.

RODRIGUES, C. F. (Coord.); FIGUEIRAS, R.; JUNQUEIRA, V. Desigualdade do rendimento e pobreza em Portugal: As consequências sociais do programa de ajustamento. Lisboa: Fundação Francisco Manuel dos Santos, 2016.

RODRIGUES, F. Novas políticas sociais novas: entre «belas» e «senãos». Locus Soci@l, n. 1, p. 90-94, 2008. 
ROSA, M. J. V. Das famílias aos agregados domésticos a partir dos factos. In: FERNANDES, O. M.; MAIA, C. (Coords.). A família portuguesa no século XXI, p. 29-37. Lisboa: Parsifal, 2015.

ROSA, M. J. V.; CHITAS, P. Portugal e a Europa: os números. Lisboa: FFMS/Relógio de Água, 2013.

SANTOS, B. S. A reinvenção solidária e participativa do Estado. Oficina do Centro de Estudos Sociais, n. 134. Coimbra: Centro de Estudos Sociais, 1999.

- Sociedade-providência ou autoritarismo social? "Editorial". Revista Crítica de Ciências Sociais, n. 42, p. i-vii, 1995.

—. Pela mão de Alice - o social e o político na pós-modernidade. Porto: Afrontamento, 1994.

(Org.). Portugal, um retrato singular. Porto: Afrontamento, 1993.

SANTOS, B. S.; FERREIRA, S. A reforma do Estado-providência entre globalizações conflituantes. In: HESPANHA, P.; CARAPINHEIRO, G. (Orgs.). Risco social e incerteza, pode o Estado social recuar mais? p. 177-225). Porto: Afrontamento, 2002.

SARACENO, C. Social inequalities in facing old-age dependency: a bi-generational perspective. Journal of European Social Policy, v. 20, n. 1, p. 32-44, 2010. Disponível em: <http://doi.org/10.1177/0958928709352540>.

SARTI, C. Famílias enredadas. In: ACOSTA, A. R.; VITALE, M. A. F. (Orgs.). Famíliaredes, laços e políticas públicas. 5. ed. p. 22-38. São Paulo: Cedpe, PUC-SP, Cortez Editora, 2010.

SAWAIA, B. B. Família e afetividade: a configuração de uma práxis ético-política, perigos e oportunidades. In: ACOSTA, A. R.; VITALE, M. A. F. (Orgs.). Família-redes, laços e políticas públicas. 5. ed. p. 39-52. São Paulo: Cedpe, PUC-SP, Cortez Editora, 2010.

SERAPIONI, M. O papel da família e das redes primárias na reestruturação das políticas sociais. Ciência \& Saúde Coletiva, v. 10 (sup), p. 243-253, 2005.

SHULTHEIS, F. The family's contribution to social reproduction: a state concern. In: Commaille, J.; Singly, F. (Ed.). The family question in the European Community. Dordrecht: Kluwer Academic Publishers, 1997.

SILVA, P. A. O modelo de welfare da Europa do sul - reflexões sobre a utilidade do conceito. Sociologia, Problemas e Práticas, n. 38, p. 25-59, 2002. 
SILVEIRA, A. S. Estado do bem-estar social e desfiliação social. Política \& Sociedade, v. 12 , n. 23, p. $145-176,2013$

SOUSA, L.; FIGUEIREDO, D. Supporting family carers of older people in Europe - the national background report for Portugal. Hamburg: Lit Verlag, 2007.

- Services for supporting family carers of elderly people in Europe: characteristics, coverage and usage. Eurofamcare, 2004.

SOUSA, L.; FIGUEIREDO, D.; CERQUEIRA, M. Envelhecer em família. Os cuidados familiares na velhice. Coleção "Idade do saber". Porto: Ambar, 2004.

SPOSATI, A.; RODRIGUES, F. Sociedade-providência: uma estratégia de regulação social consentida. Revista Crítica de Ciências Sociais, n. 42, p. 77-103, 1995.

SUNKEL, G. El papel de la família en la protección social en América Latina. Santiago de Chile: CEPAL, División de Desarrollo Social, 2006.

UNITED NATIONS (UN). World population ageing 2015. New Work: United Nations, Department of Economic and Social Affairs Population Division, 2015. Disponível em: <http://www.un.org/en/development/desa/population/publications/pdf/ ageing/WPA2015_Report.pdf>.

VASCONCELOS, P. Capital social, solidariedade familiar e desigualdade social no Portugal contemporâneo. Tese (Doutorado) - Escola de Sociologia e Políticas Públicas Escola de Tecnologias e Arquitectura (ISCTE-IUL), Lisboa, 2011. Disponível em: <http://hdl.handle.net/10071/3395>.

- Redes sociais de apoio. In: WALL, K. (Org.). Famílias em Portugal, p. 599631. Lisboa: Imprensa de Ciências Sociais, 2005.

Redes de apoio familiar e desigualdade social: estratégias de classe. Análise Social, v. 37 n. 163, p. 507-544, 2002.

VICENTE, H. T.; SOUSA, L. Relações intergeracionais e intrageracionais: a matriz relacional da família multigeracional. Revista Temática Kairós Gerontologia, v. 15, n. 2, p. 99-117, 2012.

VOLPI, R. La fine della famiglia. La rivoluzione di cui non ci siamo accorti. Milano: Mondadori, 2007.

WALL, K.; ABOIM, S.; CUNHA, V.; VASCONCELOS, P. Families and informal support networks in Portugal: the reproduction of inequality. Journal of European Social Policy, v. 11, n. 3, p. 213-233. 2001 
WORLD HEALTH ORGANIZATION (WHO). Active ageing, a policy framework. A contribution of the WHO to the Second United Nations World Assembly on ageing. Madrid: WHO, 2002.

WILLIAMS, F. Repensar as famílias. Lisboa: Principia, 2010.

YAZBECK, M. C. Pobreza e exclusão social: expressões da questão social. Temporalis, Ano III n. 3, p. 33-40, 2001.

ZANATTA, A. L. Le nuove famiglie. Felicità e rischi delle nuove scelte di vita. Bologna: II Mulino, 2008. 